\title{
Prolonged Glucocorticoid Treatment in ARDS: Impact on Intensive Care Unit-Acquired Weakness
}

\author{
Gianfranco Umberto Meduri ${ }^{1 *}$, Andreas Schwingshackl² and Greet Hermans ${ }^{3}$ \\ ${ }^{1}$ Division of Pulmonary, Critical Care, and Sleep Medicine, Department of Medicine, Memphis Veterans Affairs Medical \\ Center, Memphis, TN, USA, ${ }^{2}$ Department of Pediatrics, Division of Critical Care Medicine, Mattel Children's Hospital at \\ UCLA, Los Angeles, CA, USA, ${ }^{3}$ Laboratory of Intensive Care Medicine, Division of Cellular and Molecular Medicine, KU \\ Leuven and Medical Intensive-Care Unit, Department of General Internal Medicine University Hospitals Leuven, Leuven, \\ Belgium
}

Systemic inflammation and duration of immobilization are strong independent risk factors for the development of intensive care unit-acquired weakness (ICUAW). Activation of the pro-inflammatory transcription factor nuclear factor- $\mathrm{KB}(\mathrm{NF}-\mathrm{\kappa B})$ results in muscle wasting

OPEN ACCESS

Edited by:

Hitesh Singh Sandhu,

University of Tennessee Health

Science Center, USA

Reviewed by:

Maroun Jean Mhanna,

Case Western Reserve University,

USA

Yee Hui Mok,

KK Women's and Children's Hospital

Singapore, Singapore

Lincoln S. Smith,

University of Washington, USA

${ }^{*}$ Correspondence:

Gianfranco Umberto Meduri gmeduri@uthsc.edu

Specialty section: This article was submitted to Pediatric Critical Care, a section of the journal

Frontiers in Pediatrics

Received: 09 May 2016

Accepted: 20 June 2016

Published: 02 August 2016

Citation:

Meduri GU, Schwingshackl A and Hermans G (2016) Prolonged

Glucocorticoid Treatment in ARDS: Impact on Intensive Care Unit-Acquired Weakness.

Front. Pediatr. 4:69.

doi: 10.3389/fped.2016.00069 during disuse-induced skeletal muscle atrophy (ICU bed rest) and septic shock. In addition, NF-kB-mediated signaling plays a significant role in mechanical ventilation-induced diaphragmatic atrophy and contractile dysfunction. Older trials investigating high dose glucocorticoid treatment reported a lack of a sustained anti-inflammatory effects and an association with ICUAW. However, prolonged low-to-moderate dose glucocorticoid treatment of sepsis and ARDS is associated with a reduction in NF-kB DNA-binding, decreased transcription of inflammatory cytokines, enhanced resolution of systemic and pulmonary inflammation, leading to fewer days of mechanical ventilation, and lower mortality. Importantly, meta-analyses of a large number of randomized controlled trials investigating low-to-moderate glucocorticoid treatment in severe sepsis and ARDS found no increase in ICUAW. Furthermore, while the ARDS network trial investigating methylprednisolone treatment in persistent ARDS is frequently cited to support an association with ICUAW, a reanalysis of the data showed a similar incidence with the control group. Our review concludes that in patients with sepsis and ARDS, any potential direct harmful neuromuscular effect of glucocorticoids appears outweighed by the overall clinical improvement and reduced duration of organ failure, in particular ventilator dependency and associated immobilization, which are key risk factors for ICUAW.

Keywords: acute respiratory distress syndrome, glucocorticoid treatment, intensive care unit-acquired weakness, mechanical ventilation, survival, steroids, muscle weakness

Intensive care unit (ICU)-acquired weakness (ICUAW) is a condition that can either affect the peripheral nerves [critical illness polyneuropathy (CIP)], the skeletal muscle [critical illness myopathy (CIM)], or both and involves functional or structural changes in these tissues (1). Systemic inflammation (increased inflammatory cytokine levels) and associated organ dysfunction during early critical illness are strong independent risk factors for the development of CIM (2). As inflammatory infiltrates are rarely seen in muscle and nerve tissue in patients with ICUAW, the functional and structural damage may not be caused directly by inflammatory cell infiltration and activation, but rather stem from cytokine-driven electrophysiological alterations, endothelial and microvascular 
alterations, metabolic changes, and bio-energetic failure, ultimately leading to axonal cell death, pronounced muscle atrophy, and contractile dysfunction $(3,4)$.

In ARDS, inadequate GC-glucocorticoid receptor $\alpha(\mathrm{GR} \alpha)$ mediated downregulation of the pro-inflammatory transcription factor nuclear factor- $\kappa \mathrm{B}(\mathrm{NF}-\kappa \mathrm{B})$ in circulating and tissueresident cells leads over time ( $>4$ weeks) to a persistent elevation in plasma inflammatory cytokine levels indicating dysregulated systemic inflammation (5). NF- $\mathrm{\kappa B}$ signaling is also involved in muscle wasting during disuse-induced skeletal muscle atrophy (ICU bed rest) and septic shock (6) and is a critical regulator of the catabolic response to $\mathrm{TNF} \alpha(7)$. NF- $\kappa \mathrm{B}$ activation also plays a significant signaling role in mechanical ventilation-induced diaphragmatic atrophy and contractile dysfunction by increasing transcription of specific atrophy-related genes (8). Hence, dysregulated systemic inflammation not only leads to delayed resolution of ARDS (5) but also contributes to the development of ICUAW.

Another important risk factor for ICUAW is the duration of immobilization $(9,10)$. ICUAW is often associated with respiratory muscle weakness (11). The phrenic nerve and diaphragm show similar electrophysiological and anatomo-pathological abnormalities as the peripheral nerves and muscles, contributing to delayed weaning from mechanical ventilation $(12,13)$. In turn, prolonged duration of mechanical ventilation itself can further exacerbate the weakness and atrophy of the diaphragm, which is often the clinical problem with which these patients present (10, 14). In addition to prolonged mechanical ventilation, ICUAW is also associated with longer ICU stay, increased mortality (3) as well as with long-term consequences beyond the hospitalization phase, which contribute substantially to the long-term financial burden of ARDS survivors on the health-care budget $(10,15,16)$.

Although myopathy is a well-known adverse effect of chronic glucocorticoid administration (17), it is important to recognize that in fact glucocorticoids could potentially downregulate detrimental inflammatory pathways involved in ICUAW (1) and provide a protective effect if hyperglycemia is controlled (18). Experimental ARDS is associated with a significant reduction in lung tissue GR $\alpha$ expression (19-21) and increase in GR $\beta$ mRNA (20) leading to decreased GR $\alpha$ nuclear translocation (20). In these experiments, low-dose glucocorticoid treatment, contrary to placebo, restored GR $\alpha$ number and function leading to the resolution of pulmonary inflammation $(21,22)$. In an ex vivo ARDS study, prolonged methylprednisolone treatment, contrary to placebo, was associated with upregulation in $\mathrm{GR} \alpha$, significant increases in GC-GR $\alpha$-mediated activities (GR $\alpha$ binding to NF- $\kappa \mathrm{B}, \mathrm{GR} \alpha$ binding to GC response element on DNA, stimulation of inhibitory protein I $\kappa \mathrm{B} \alpha$, and stimulation of IL-10 transcription), and significant reductions in NF- $\mathrm{BB}-\kappa \mathrm{b}$ DNAbinding and the transcription of TNF- $\alpha$ and IL-1 $\beta$ (23). ARDS patients randomized to prolonged methylprednisolone treatment, contrary to placebo, demonstrated a rapid and sustained reduction in markers of systemic inflammation $(23,24)$.

Recent guidelines $(25,26)$ and reviews $(27)$ have provided an incomplete representation of the available evidence on glucocorticoid treatment in ARDS by citing imprecise meta-analysis (28) or contradictory results among meta-analyses $(28,29)$. This is having significant repercussions for the care of patients with ARDS and necessitates a clarification. A meaningful analysis of glucocorticoid treatment in ARDS must be founded on present understanding of disease pathophysiology and fundamentals of pharmacological treatment (5). The beneficial effects of glucocorticoid therapy in sepsis and ARDS are affected by four critical components of therapy: timing of initiation, dosage, duration of treatment, and tapering. In the 1980s, based on a faulty laboratory model (30), clinical investigations focused on a 1-day course of massive doses of methylprednisolone for prevention (31) or treatment of ARDS (32). Patients received $120 \mathrm{mg} / \mathrm{kg}$ of methylprednisolone $(31,32)$, equivalent to $\sim 1$-year of prednisone $20 \mathrm{mg}$ daily. The prevailing fundamental principle (1950-1980) that treatment should be continued until disease resolution was omitted from the design of these negative trials (30). The findings of these randomized controlled trials (RCTs) halted the progress of the field (30). Surprisingly, these obsolete trials are often combined with contemporary trials in meta-analyses, despite serious inconsistency $(28,33)$ often producing misleading results. Furthermore, these meta-analyses also include selected retrospective cohort studies increasing the risk for imprecision $(34,35)$. Over the last 20 years, RCTs have instead investigated only low-to-moderate daily dosage ( $\leq 1 \mathrm{mg} / \mathrm{kg}$ for early ARDS and $\leq 2 \mathrm{mg} / \mathrm{kg}$ of methylprednisolone-equivalent for late ARDS) for 1-4 weeks; meaningful meta-analyses should focus on these RCTs that are relevant today.

Our recent systematic review (36) included trial and patientlevel meta-analyses of eight RCTs $(n=619)$ investigating prolonged low-dose glucocorticoid treatment in ARDS. With high certainty, glucocorticoids improved time to extubation (10.1 fewer days, $95 \%$ confidence interval -13.1 to -7.1$)$ and mechanical ventilation-free days at day 28 (5.8 more days, $95 \%$ confidence interval 3.8-11.5) and with moderate certainty, reduced inhospital mortality by $24 \%$ (95\% confidence interval $2-41 \%$ ), for those randomized before day 14 of ARDS. Importantly, avoiding sudden discontinuation of methylprednisolone administration after extubation is essential to preserve improvement (36). For patients randomized after day 13 of ARDS, the ARDS network original report (37) found increased 60-day mortality. However, this subgroup $(n=48)$ had an uncharacteristically low mortality $(8 \%)$ and large differences in baseline characteristics (38). When the analysis was adjusted for the imbalances at baseline, the mortality difference lost significance ( 25.6 vs. $13.2 \%$; $p=0.325$ ) (39). The results show that our meta-analysis (36) is also consistent with a recent meta-analysis of 13 RCTs $(n=2,005)$ investigating low-dose glucocorticoid treatment in community-acquired pneumonia (leading cause of ARDS) (40). In addition to a potential reduction in mortality, glucocorticoid treatment reduced the risk of progression to ARDS (relative risk 0.24, 95\% confidence interval $0.10-0.56$ ) or need for mechanical ventilation (relative risk $0.45,95 \%$ confidence interval $0.26-0.79$ ) - both moderate certainty (40).

Although some reports identified glucocorticoid administration as a significant risk factor for ICUAW $(12,41)$ or short- to medium-term functional outcome $(42,43)$, most were unable to demonstrate an association between prolonged low-to-moderate dose glucocorticoid treatment and electrophysiologically or 
clinically proven neuromuscular dysfunction $(2,15,18,44-48)$ or with any physical outcome at discharge and up to 2 years following ARDS (15). Meta-analyses limited to randomized trials investigating prolonged glucocorticoid treatment in ARDS (29) and sepsis (49) have reported a similar rate of ICUAW in the control and treated groups. Nevertheless, the ARDS network trial (37) is frequently cited for concluding that methylprednisolone is associated with a higher rate of neuromuscular weakness. However, the actual results of the trial (37) show a similar rate (placebo vs. methylprednisolone) of weakness [21 (22\%) vs. $26(30 \%)$; $p=0.20$ ] and similar 60-day mortality (ARDSnet02 Dataset) for those with weakness [3 (14\%) vs. $2(8 \%)$ ]. In a subsequent publication (45), after removal of six patients (five randomized to methylprednisolone) with documented weakness at study entry, the ARDS network authors confirmed that methylprednisolone was not associated with increased incidence of weakness [21 (24\%) vs. 20 (22\%)]. Importantly, in the Appendix of the original publication (37), Table 7 showed that median duration (days) of MV (placebo vs. methylprednisolone) was appreciably lower for those randomized to methylprednisolone with [26 (14-38) vs. $15(12-22)$ ] or without weakness [16 (9-30.5) vs. $8.5(5-21)$ ], respectively.

Furthermore, the original ARDS network publication (37) placed much attention to a subgroup of methylprednisolone patients with weakness reported as a serious adverse event (0 vs. 9; $p<0.001)$. An adverse event or suspected adverse reaction must be reported to the sponsor within $72 \mathrm{~h}$ of identification and is considered "serious" (SAE) if, in the view of either the investigator or sponsor, it results or may result in a serious outcome, such as death or prolongation of existing hospitalization (50). However, the methylprednisolone patients in question did not have increased duration of mechanical ventilation or death in comparison to the control group. The methylprednisolone-treated patients with SAE related to weakness had a median duration on initial mechanical ventilation of 16.5 days (7-28) and only one death. The death occurred in a patient with high severity indices (APACHE III 99, SOFA score 14) with study drug removed without tapering the day after successful extubation (study day 14) that returned to MV 3 days later (without reinstitution of study drug in the presence of possible adrenal suppression) and died on study day 20 (ARDSnet02 Dataset).

In summary, while ICUAW is an independent predictor of prolonged weaning (51) and is associated with increased

\section{REFERENCES}

1. Friedrich O, Reid MB, Van den Berghe G, Vanhorebeek I, Hermans G, Rich MM, et al. The sick and the weak: neuropathies/myopathies in the critically ill. Physiol Rev (2015) 95:1025-109. doi:10.1152/ physrev.00028.2014

2. Weber-Carstens S, Deja M, Koch S, Spranger J, Bubser F, Wernecke KD, et al. Risk factors in critical illness myopathy during the early course of critical illness: a prospective observational study. Crit Care (2010) 14:R119. doi:10.1186/ cc9074

3. Witteveen E, Wieske L, Verhamme C, Schultz MJ, van Schaik IN, Horn $\mathrm{J}$. Muscle and nerve inflammation in intensive care unit-acquired weakness: a systematic translational review. J Neurol Sci (2014) 345:15-25. doi:10.1016/j. jns.2014.07.014 mortality, randomized ARDS trials investigating prolonged low-dose glucocorticoid treatment have consistently reported a sizable and significant increase in mechanical ventilation-free days and reduction in hospital mortality for those randomized before day 14 (36). Based on these observations, it is reasonable to conclude that glucocorticoid treatment-associated downregulation of systemic inflammation in ARDS does not induce clinically relevant neuromuscular dysfunction. Alternatively, any potential direct harmful neuromuscular effect of glucocorticoids appears outweighed by the overall clinical improvement and reduced duration of organ failure, in particular ventilator dependency and associated immobilization, which are key risk factors for ICUAW.

\section{AUTHORS CONTRIBUTIONS}

The authors co-wrote, reviewed, and approved the final report.

\section{ACKNOWLEDGMENTS}

The NHLBI ARDSnetwork graciously provided and assisted with the ARDSnet02 Dataset on the "Efficacy of Corticosteroids as Rescue Therapy for the Late Phase of Acute Respiratory Distress Syndrome (LaSRS).”

\section{FUNDING}

This material is the result of work supported with the resources and use of facilities at the Memphis VA Medical Center. The contents of this commentary do not represent the views of the U.S. Department of Veterans Affairs or the United States Government. Funding for the respective trials was disclosed in the original publications. None of the sponsors had any role in the design and conduct of the study, the collection, management, analysis and interpretation of the data, the preparation, review, or approval of the report, or the decision to submit the manuscript for publication. The corresponding author had full access to all the data in the study and had final responsibility for the decision to submit for publication. GH holds a Senior Clinical Investigator Fellowship from the FWO, Research Foundation Flanders, Belgium.

4. Langhans C, Weber-Carstens S, Schmidt F, Hamati J, Kny M, Zhu X, et al. Inflammation-induced acute phase response in skeletal muscle and critical illness myopathy. PLoS One (2014) 9:e92048. doi:10.1371/journal.pone. 0092048

5. Meduri GU, Annane D, Chrousos GP, Marik PE, Sinclair SE. Activation and regulation of systemic inflammation in ARDS: rationale for prolonged glucocorticoid therapy. Chest (2009) 136:1631-43. doi:10.1378/ chest.08-2408

6. van Hees HW, Schellekens WJ, Linkels M, Leenders F, Zoll J, Donders R, et al. Plasma from septic shock patients induces loss of muscle protein. Crit Care (2011) 15:R233. doi:10.1186/cc10475

7. Li YP, Reid MB. NF-kappa B mediates the protein loss induced by TNF-alpha in differentiated skeletal muscle myotubes. Am J Physiol Regul Integr Comp Physiol (2000) 279:R1165-70. 
8. Smuder AJ, Hudson MB, Nelson WB, Kavazis AN, Powers SK. Nuclear factor-kappaB signaling contributes to mechanical ventilation-induced diaphragm weakness*. Crit Care Med (2012) 40:927-34. doi:10.1097/ CCM.0b013e3182374a84

9. de Jonghe B, Lacherade JC, Sharshar T, Outin H. Intensive care unit-acquired weakness: risk factors and prevention. Crit Care Med (2009) 37:S309-15. doi:10.1097/CCM.0b013e3181b6e64c

10. Hermans G, Van den Berghe G. Clinical review: intensive care unit acquired weakness. Crit Care (2015) 19:274. doi:10.1186/s13054-015-0993-7

11. Jung B, Moury PH, Mahul M, de Jong A, Galia F, Prades A, et al. Diaphragmatic dysfunction in patients with ICU-acquired weakness and its impact on extubation failure. Intensive Care Med (2015) 19:274. doi:10.1007/s00134-015-4125-2

12. De Jonghe B, Sharshar T, Lefaucheur JP, Authier FJ, Durand-Zaleski I, Boussarsar $\mathrm{M}$, et al. Paresis acquired in the intensive care unit: a prospective multicenter study. JAMA (2002) 288:2859-67. doi:10.1001/jama.288.22.2859

13. De Jonghe B, Bastuji-Garin S, Durand MC, Malissin I, Rodrigues P, Cerf C, et al. Respiratory weakness is associated with limb weakness and delayed weaning in critical illness. Crit Care Med (2007) 35:2007-15. doi:10.1097/01. ccm.0000281450.01881.d8

14. Petrof BJ, Hussain SN. Ventilator-induced diaphragmatic dysfunction: what have we learned? Curr Opin Crit Care (2016) 22:67-72. doi:10.1097/ MCC. 0000000000000272

15. Fan E, Dowdy DW, Colantuoni E, Mendez-Tellez PA, Sevransky JE, Shanholtz C, et al. Physical complications in acute lung injury survivors: a two-year longitudinal prospective study. Crit Care Med (2014) 42:849-59. doi:10.1097/CCM.0000000000000040

16. Hermans G, Van Mechelen H, Clerckx B, Vanhullebusch T, Mesotten D, Wilmer A, et al. Acute outcomes and 1-year mortality of intensive care unit-acquired weakness. A cohort study and propensity-matched analysis. Am J Respir Crit Care Med (2014) 190:410-20. doi:10.1164/rccm.201312-2257OC

17. Patt H, Bandgar T, Lila A, Shah N. Management issues with exogenous steroid therapy. Indian J Endocrinol Metab (2013) 17:S612-7. doi:10.4103/2230-8210.123548

18. Hermans G, Wilmer A, Meersseman W, Milants I, Wouters PJ, Bobbaers H, et al. Impact of intensive insulin therapy on neuromuscular complications and ventilator dependency in the medical intensive care unit. Am J Respir Crit Care Med (2007) 175:480-9. doi:10.1164/rccm.200605-665OC

19. Zhou T, Fan XM, Wang YQ, Qi YJ, Chen H, Qian SY. [Effects of different doses of hydrocortisone on acute lung injury in rats with early septic shock induced by Escherichia coli]. Zhonghua Er Ke Za Zhi (2004) 42:644-8.

20. Kamiyama K, Matsuda N, Yamamoto S, Takano K, Takano Y, Yamazaki H, et al. Modulation of glucocorticoid receptor expression, inflammation, and cell apoptosis in septic guinea pig lungs using methylprednisolone. Am J Physiol Lung Cell Mol Physiol (2008) 295:L998-1006. doi:10.1152/ajplung.00459.2007

21. Wang XQ, Zhou X, Zhou Y, Rong L, Gao L, Xu W. Low-dose dexamethasone alleviates lipopolysaccharide-induced acute lung injury in rats and upregulates pulmonary glucocorticoid receptors. Respirology (2008) 13:772-80. doi:10.1111/j.1440-1843.2008.01344.x

22. Zhang Y, Zuo W, Rong Q, Teng G, Zhang YM. Glucocorticoid receptor expression on acute lung injury induced by endotoxin in rats. World J Emerg Med (2010) 1:65-9.

23. Meduri GU, Tolley EA, Chrousos GP, Stentz F. Prolonged methylprednisolone treatment suppresses systemic inflammation in patients with unresolving acute respiratory distress syndrome. Evidence for inadequate endogenous glucocorticoid secretion and inflammation-induced immune cell resistance to glucocorticoids. Am J Respir Crit Care Med (2002) 165:983-91. doi:10.1164/ ajrccm.165.7.2106014

24. Seam N, Meduri GU, Wang H, Nylen ES, Sun J, Schultz MJ, et al. Effects of methylprednisolone infusion on markers of inflammation, coagulation, and angiogenesis in early acute respiratory distress syndrome. Crit Care Med (2012) 40:495-501. doi:10.1097/CCM.0b013e318232da5e

25. Claesson J, Freundlich M, Gunnarsson I, Laake J, Møller M, Vandvik P, et al. Scandinavian clinical practice guideline on fluid and drug therapy in adults with acute respiratory distress syndrome. Acta Anaesthesiol Scand (2016) 60:697-709. doi:10.1111/aas.12713

26. Cho YJ, Moon JY, Shin ES, Kim JH, Jung H, Park SY, et al. Clinical practice guideline of acute respiratory distress syndrome. Korean J Crit Care Med (2016) 31:76-100. doi:10.4266/kjccm.2016.31.2.76
27. Sweeney RM, McAuley DF. Acute respiratory distress syndrome. Lancet (2016). doi:10.1016/S0140-6736(16)00578-X

28. Ruan SY, Lin HH, Huang CT, Kuo PH, Wu HD, Yu CJ. Exploring the heterogeneity of effects of corticosteroids on acute respiratory distress syndrome: a systematic review and meta-analysis. Crit Care (2014) 18:R63. doi:10.1186/ cc13819

29. Tang B, Craig J, Eslick G, Seppelt I, McLean A. Use of corticosteroids in acute lung injury and acute respiratory distress syndrome: a systematic review and meta-analysis. Crit Care Med (2009) 37:1594-603. doi:10.1097/ CCM.0b013e3181b41b9b

30. Meduri GU. An historical review of glucocorticoid treatment in sepsis. Disease pathophysiology and the design of treatment investigation. Sepsis (1999) 3:21-38. doi:10.1023/A:1009870524359

31. Luce JM, Montgomery AB, Marks JD, Turner J, Metz CA, Murray JF. Ineffectiveness of high-dose methylprednisolone in preventing parenchymal lung injury and improving mortality in patients with septic shock. Am Rev Respir Dis (1988) 138:62-8. doi:10.1164/ajrccm/138.1.62

32. Bernard GR, Luce JM, Sprung CL, Rinaldo JE, Tate RM, Sibbald WJ, et al. High-dose corticosteroids in patients with the adult respiratory distress syndrome. N Engl J Med (1987) 317:1565-70. doi:10.1056/ NEJM198712173172504

33. Horita N, Hashimoto S, Miyazawa N, Fujita H, Kojima R, Inoue M, et al. Impact of corticosteroids on mortality in patients with acute respiratory distress syndrome: a systematic review and meta-analysis. Intern Med (2015) 54:1473-9. doi:10.2169/internalmedicine.54.4015

34. Annane D. Pro: the illegitimate crusade against corticosteroids for severe H1N1 pneumonia. Am J Respir Crit Care Med (2011) 183:1125-6. doi:10.1164/ rccm.201102-0345ED

35. Schwingshackl A, Meduri GU, Kimura D, Cormier SA, Anand KJ. Corticosteroids in pediatric ARDS: all cards on the table. Intensive Care Med (2015) 41:2036-37. doi:10.1007/s00134-015-4027-3

36. Meduri GU, Bridges L, Shih MC, Marik PE, Siemieniuk RA, Kocak M. Prolonged glucocorticoid treatment is associated with improved ARDS outcomes: analysis of individual patients' data from four randomized trials and trial-level meta-analysis of the updated literature. Intensive Care Med (2016) 42:829-40. doi:10.1007/s00134-015-4095-4

37. Steinberg KP, Hudson LD, Goodman RB, Hough CL, Lanken PN, Hyzy R, et al. Efficacy and safety of corticosteroids for persistent acute respiratory distress syndrome. $N$ Engl J Med (2006) 354:1671-84. doi:10.1056/ NEJMoa051693

38. Meduri GU, Marik PE, Chrousos GP, Pastores SM, Arlt W, Beishuizen A, et al. Steroid treatment in ARDS: a critical appraisal of the ARDS network trial and the recent literature. Intensive Care Med (2008) 34:61-9. doi:10.1007/ s00134-007-0933-3

39. Thompson BT, Ancukiewicz M, Hudson LD, Steinberg KP, Bernard GR. Steroid treatment for persistent ARDS: a word of caution. Crit Care (2007) 11:425. doi:10.1186/cc6186

40. Siemieniuk RA, Meade MO, Alonso-Coello P, Briel M, Evaniew N, Prasad M, et al. Corticosteroid therapy for patients hospitalized with communityacquired pneumonia: a systematic review and meta-analysis. Ann Intern Med (2015) 163:519-28. doi:10.7326/M15-0715

41. Hermans G, Casaer MP, Clerckx B, Guiza F, Vanhullebusch T, Derde $\mathrm{S}$, et al. Effect of tolerating macronutrient deficit on the development of intensive-care unit acquired weakness: a subanalysis of the EPaNIC trial. Lancet Respir Med (2013) 1:621-9. doi:10.1016/S2213-2600(13) 70183-8

42. Herridge MS, Cheung AM, Tansey CM, Matte-Martyn A, Diaz-Granados $\mathrm{N}$, Al-Saidi F, et al. One-year outcomes in survivors of the acute respiratory distress syndrome. N Engl J Med (2003) 348:683-93. doi:10.1056/ NEJMoa022450

43. Needham DM, Wozniak AW, Hough CL, Morris PE, Dinglas VD, Jackson JC, et al. Risk factors for physical impairment after acute lung injury in a national, multicenter study. Am J Respir Crit Care Med (2014) 189:1214-24. doi:10.1164/ rccm.201401-0158OC

44. Stevens RD, Dowdy DW, Michaels RK, Mendez-Tellez PA, Pronovost PJ, Needham DM. Neuromuscular dysfunction acquired in critical illness: a systematic review. Intensive Care Med (2007) 33:1876-91. doi:10.1007/ s00134-007-0772-2 
45. Hough CL, Steinberg KP, Taylor Thompson B, Rubenfeld GD, Hudson LD. Intensive care unit-acquired neuromyopathy and corticosteroids in survivors of persistent ARDS. Intensive Care Med (2009) 35:63-8. doi:10.1007/ s00134-008-1304-4

46. Bednarik J, Vondracek P, Dusek L, Moravcova E, Cundrle I. Risk factors for critical illness polyneuromyopathy. J Neurol (2005) 252:343-51. doi:10.1007/ s00415-005-0654-x

47. de Letter MA, Schmitz PI, Visser LH, Verheul FA, Schellens RL, Op de Coul DA, et al. Risk factors for the development of polyneuropathy and myopathy in critically ill patients. Crit Care Med (2001) 29:2281-6. doi:10.1097/00003246-200112000-00008

48. Nanas S, Kritikos K, Angelopoulos E, Siafaka A, Tsikriki S, Poriazi M, et al. Predisposing factors for critical illness polyneuromyopathy in a multidisciplinary intensive care unit. Acta Neurol Scand (2008) 118:175-81. doi:10.1111/j.1600-0404.2008.00996.x

49. Annane D, Bellissant E, Bollaert PE, Briegel J, Keh D, Kupfer Y. Corticosteroids for treating sepsis. Cochrane Database Syst Rev (2015) 12:CD002243. doi:10.1002/14651858.CD002243.pub3
50. Code of Federal Regulations. Title 21. In: Administration USFaD, editor. U.S. Department of Health and Human Services, Subcharter D-Drugs for Human Use. Vol. 5. Report Number 21CFR312.32 (2015). Available from: http://www. accessdata.fda.gov/scripts/cdrh/cfdocs/cfcfr/CFRSearch.cfm?FR=312.32

51. De Jonghe B, Bastuji-Garin S, Sharshar T, Outin H, Brochard L. Does ICUacquired paresis lengthen weaning from mechanical ventilation? Intensive Care Med (2004) 30:1117-21. doi:10.1007/s00134-004-2174-z

Conflict of Interest Statement: The authors have no competing interests to declare or any real or perceived financial interest in any product or commodity mentioned in this paper.

Copyright (c) 2016 Meduri, Schwingshackl and Hermans. This is an open-access article distributed under the terms of the Creative Commons Attribution License (CC $B Y)$. The use, distribution or reproduction in other forums is permitted, provided the original author(s) or licensor are credited and that the original publication in this journal is cited, in accordance with accepted academic practice. No use, distribution or reproduction is permitted which does not comply with these terms. 